\title{
Technology Supporting Nursing at Homecare - Seems to Be Lacking
}

\author{
Eija KIVEKÄS ${ }^{\mathrm{a}, 1}$, Santtu MIKKONEN ${ }^{\mathrm{b}}$, Samuli KOPONEN ${ }^{\mathrm{a}}$ and Kaija SARANTO ${ }^{\mathrm{a}}$ \\ ${ }^{a}$ Department of Health and Social Management, University of Eastern Finland, \\ Kuopio, Finland \\ ${ }^{\mathrm{b}}$ Department of Applied Physics, University of Eastern Finland, Kuopio, Finland
}

\begin{abstract}
The use of welfare technologies in the home setting has drawn increased attention in healthcare. From a historical perspective, medical technologies were designed for hospital settings. Digitalization and internet of things have changed the structure of our society. The aim of this paper is to describe the factors that determine a user's intent to adopt new welfare technologies in the context of homecare. The phenomenon was being examined by the unified theory of acceptance and use of technology. This study was to show that performance expectancy, effort expectancy, and facilitating conditions are significant factors in determining a user's intention to use new welfare technologies. While, the use of welfare technologies was rare in homecare.
\end{abstract}

Keywords: welfare, technology, homecare, UTAUT

\section{Introduction}

Digitalization and Internet of things (IoT) have changed the structure of our society. This structural change has a continuous effect on job descriptions in the healthcare sector. The main challenges in launching and using technology are a lack of usability, inadequate communication between participants, and poorly resourced implementation processes. The need for competence is affected by internal changes in professional operating environments that arise from the knowledge base in those professions. Technology use in healthcare always create challenges in nurse-patient relationship. This creates external expectations for professional competencies [1].

Theoretical models have been developed to understand the acceptance and use of information systems (IS). The acceptance and use of information systems and information technology (IT) have received extensive attention from researchers in the last few decades [2]. Different technological and contextual factors that influence the adoption of technologies in individual and organizational contexts has been focused by various theories.

Venkatesh and his colleagues (2003) developed a unified model that brings together alternative views on user and innovation acceptance [3]. The unified theory of acceptance and use of technology (UTAUT) is a behavioral model that aims to explain the behavior of people or organizations in their use of IT/IS. The UTAUT has four key constructs:

\footnotetext{
${ }^{1}$ Corresponding Author, Eija Kivekäs, Department of Health and Social Management, University of Eastern Finland, Kuopio Campus, 70211 Kuopio, Finland; E-mail: eija.kivekas@uef.fi.
} 
performance expectancy, effort expectancy, social influence, and facilitating conditions. These are direct determinants of behavioral intention and ultimate behavior and are, in turn, moderated by gender, age, experience, and voluntariness of use [3]. Performance expectancy defines as the level to which an individual believes that using an IT system will help them improve their job performance, whereas effort expectancy is the level of ease associated with the use of such a system. Social influence defines as the degree to which an individual's important relations believe that the individual should use the system, and facilitating conditions are the measure of infrastructural support available for use of the system. Performance expectancy, effort expectancy, social influence, and facilitating conditions have both a direct and indirect influence on behavioral intention to use IT systems. The UTAUT model also posits that the attitudes construct has both direct and indirect (via behavioral intention) effects on use behavior. [3.]

The focus of this study is for understanding individual adoption of IT/IS in homecare using the UTAUT. The purpose of this paper is to describe the factors that determine nurses and students intent to adopt new welfare technologies in homecare settings after educational sessions.

\section{Welfare Technology in Homecare}

Welfare technologies are being increasingly used in elderly care. Assistive technologies have been positively evaluated by elderly clients, healthcare professionals, and family members [1]. In Finland, municipalities have a legislative responsibility to organize homecare services in collaboration with private sectors, various associations, and older clients to plan and realize homecare services for older clients at home by offering care based on clients' personal needs [4]. Therefore, the goal of welfare services for older people is to provide homecare services that support independent living and maximize clients' resources. This requires homecare services to make meaningful activities and social relationships possible in relation to clients' quality of life and psychological wellbeing despite their decline in functional, cognitive, psychological, and social abilities and their need for the highest level of care $[1,2,5]$. In general, elderly care can and needs to develop using welfare technology and robotics. The elderly population is living at home longer, requires more nursing and care resources.

An increasing number of elderly people have a pressing need for solutions to how independent living and high-quality care can be achieved in the circumstances where the number of nurses is decreasing and resources are becoming limited [4,5,6]. Coco and colleagues showed that according to patients, interacting with robots has been useful and pleasant [4]. Patients do not consider them replacements for human interactions [4]. The attitudes of care personnel have to also been considered, as we do in this article. The model of UTAUT is explored through five hypotheses, which described relationships of four key constructs by the model (Table 1).

\section{Methodology}

The questionnaire used in this study was modified from the question items of Venkatesh et al. $[3,7]$. The questionnaire was pretested on a technology pilot in homecare and was then modified according to their feedback. All items, excluding the use behavior, were measured using a five-point Likert scale, with the anchors being strongly disagree and 
strongly agree. Examples, an item of performance expectancy "Using welfare technology increases my productivity" and an item of effort expectancy "Learning how to use welfare technology is easy for me" were used in the measurements. The use behavior was measured using tripartite scale (daily - weekly - rarely). Variables' internal consistency were assessed using Cronbach's alpha and a sum variable were constructed for performance expectancy $(\alpha=.942)$, effort expectancy $(\alpha=.888)$, behavioral intention $(\alpha=.665)$ and facilitating conditions $(\alpha=.805)$. Data collection was carried out in connection with the training of the WelTech project [8]. This project was launched to develop welfare technology training courses for social and healthcare professionals and students. The questionnaire was used at the end of the course in the WelTech project.

To analyze the data, we use SEM in Amos 25 (IBM SPSS). SEM is a combination of confirmatory factor analysis (CFA) and path analysis. Confirmatory factor analysis allows the specification of construct-item relationships so that they can be tested against the UTAUT theory. CFA and SEM are therefore used for testing the UTAUT theory. We use a root-mean-square error (RMSE) less than or equal to 0.08 and a comparative fit index (CFI) greater than or equal to 0.95 . We also use a Bentler-Bonett Normed Fit Index (NFI) and an incremental fit index (IFI) greater than or equal to 0.90 to indicate that the model fits the data adequately [9].

\section{Results}

A total of 124 participants answered the questionnaire in 2019. The subjects were comprised of 102 women (84\%) and 20 men (16\%). They included 61 social and healthcare professionals (50\%), 24 other professionals (19\%), 22 students (18\%) and 17 missing information $(13 \%)$. One third of the participants $(n=44)$ were less than 27 years old, nearly one third of the participants $(n=36)$ were between 28 and 37 years, and one third of the participants $(n=44)$ were more than 38 years old. We examined our proposed research model with the key constructs of performance expectancy, effort expectancy, social influence, facilitating conditions in relation to behavioral intention, and use behavior. The results of SEM are shown in Fig. 1, and the results of the hypotheses are presented in Table 1. Performance expectancy proved a strong construct, whereas social influence did not prove to be effective in this study.

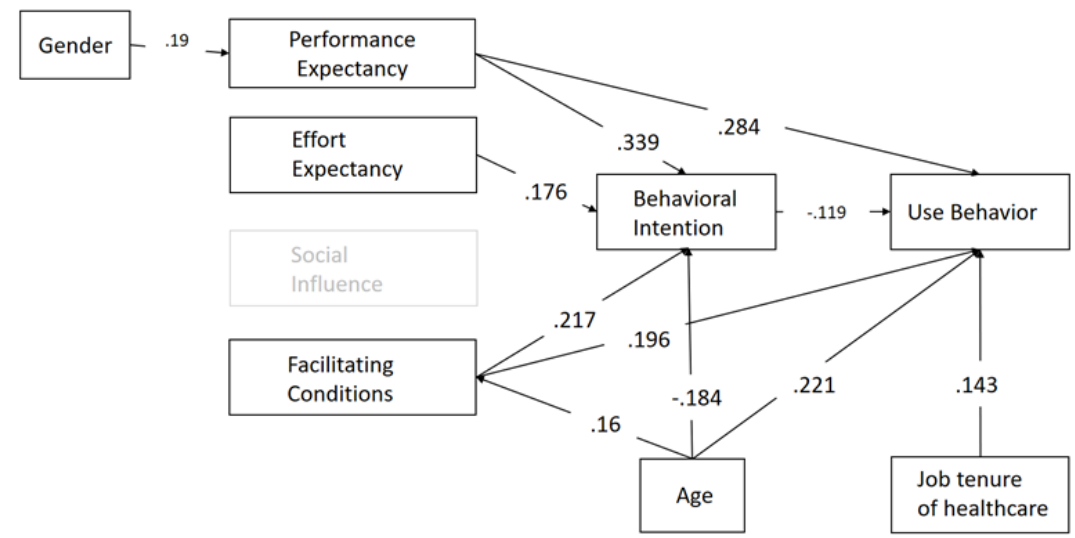

Figure 1. Assessment of the research model (standardized solution, $p<0.5$, RMSEA $=.023$, CFI $=.996$, $\mathrm{NFI}=.942, \mathrm{IFI}=.996)$. 
The various indices confirmed that the UTAUT model was supported (Table 1). Performance expectancy, effort expectancy and facilitating conditions were associated with behavioral intention. Performance expectancy and facilitating conditions were associated with use behavior. Behavioral intention weekly associated with use behavior, and social influence did not have any statistical correlation in this data.

Table 1. Results of examining the hypotheses.

\begin{tabular}{lll}
\hline Hypotheses & Results \\
\hline H1 & Performance expectancy positively affects users' intention to use welfare technology in homecare. & Supported \\
H2 & Effort expectancy positively affects users' intention to use welfare technology in homecare & Supported \\
H3 & Social influence positively affects users' intention to use welfare technology in homecare. & Not supported \\
H4 & $\begin{array}{l}\text { Facilitating conditions of welfare technology positively affects users' use behaviors of actually } \\
\text { using welfare technology in homecare }\end{array}$ & Supported \\
H5 $\begin{array}{l}\text { Users' behavioral intentions to use welfare technology in homecare positively affect the users' use } \\
\text { behavior of actually using welfare technology in homecare. }\end{array}$ & Not supported \\
\hline
\end{tabular}

\section{Discussion and Conclusion}

The use of technology has been perceived to be useful, particularly when it diminished the workload of care personnel [5] and when the solutions were user-friendly [1]. This study shows that performance expectancy, effort expectancy, and facilitating conditions are significant factors in determining a user's intention to use new welfare technologies. The results are in line with previous studies $[5,6]$. Social influence did not prove to be as strong a factor in the model as we expected. Previous research results for UTAUT relationships have shown inconsistencies [2,7]. Weakly association between behavior intention and use behavior could revealed that technology is lacking in homecare.

The weak social influence factor could reflect the role on management support, which seemed to be weak in implementing welfare technologies. It is important to help social and healthcare personnel accept technology and to reduce fears that technology could take their jobs $[4,6]$. Education plays a crucial role in technology acceptance, and it is important that care personnel notice that welfare technology is credible. Education is crucial in changing attitudes and helping social and healthcare personnel understand that welfare technologies may perform routine tasks, allowing personnel to focus on providing improved care. The WelTech project was launched to develop welfare technology training courses for social and healthcare professionals and students. This study proved that performance expectancy was the most important factor in the early stages of development.

The UTAUT model has been extensively tested in various fields and promises to be a great tool for analyzing users' acceptance of health technology [6]. However, the UTAUT does have some limitations; an analysis of acknowledged limitations across studies indicates that focusing on a single subject, community, organization, department, or age group has been the most widespread constraint [7]. The limitations in this study included a small amount of data, consisting only of first students. The training course continues, and this study could be seen as a pilot study. Another limitation is that welfare technologies are still rare in homecare, and therefore, the answers from this study could largely be a view of the future. 
The UTAUT also demonstrates the role of facilitating conditions and intentions for directly predicting use behavior, citing the theory to support the proposed relationships across a range of contexts, including social and healthcare professionals' behavioral intentions toward the use of welfare technology in homecare in general. To ensure the content validity of the scales, the selected items must represent the concept about which generalizations are to be made. Therefore, items selected for the constructs were adapted from previous studies and modified to fit welfare-technology adoption in the context of homecare. Our study shows that the UTAUT is a useful framework. In the future, it should be extended with relevant constructs so that it can contribute to the understanding of important phenomena.

\section{References}

[1] Melkas H, Hennala L, Pekkarinen S, Kyrki V. Impacts of robot implementation on care personnel and clients in elderly care institutions. Int J of Med Inf, 2020; 134(104041).

[2] Dwivedu YK, Rana NP, Tamilmani K, Raman R. A meta-analysis based modified unified theory of acceptance and use of technology (meta-UTAUT): A review of emerging literature. Current Opinion in Psychology, 2020; 36:13-8.

[3] Venkatesh V, Morris MG, Davis GB, Davis FD. Use acceptance of information technology: Towards a unified view. MIS Quarterly, 2003; 27(3):425-78.

[4] Coco K, Kangasniemi M, Rantanen T. Care personnel's attitudes and fears toward care robots in elderly care: A comparison of data from the Care Personnel in Finland and Japan Journal of Nursing Scholarship, 2018; 50(6):634-44. doi:10.1111/jnu.12435

[5] Peek STM, Wouters EJM, van Hoof J, Lujikx KG, Boeije HR, Vrijhoef HJM. Factors influencing acceptance of technology for aging in place: A systematic review. Int J Med Inf, 2014; 83:235-48.

[6] Magsamen-Conrad K, Upadhyaya S, Youngnyo Joa C, Dowd J. Bridging the divide: Using UTAUT to predict multigenerational tablet adoption practices. Computers in Human Behavior, 2015; 50:186-96.

[7] Venkatesh V, Thong JY, Xu X. Consumer acceptance and use of information technology: Extending the unified theory of acceptance and use of technology. Forthcoming in MIS Quarterly, 2012; 36(1):157-78.

[8] WelTech project. Wellbeing technology education product: Introduction and training 2018-2020. Savonia University of Applied Sciences. Retrieved from: https://portal.savonia.fi/amk/fi/tutkimus-jakehittaminen/projekti-ja-hanketoiminta/projektit-ja-hankkeet?id=973.

[9] Hair J, Black W, Babin B, Anderson R. Multivariate data analysis. A global perspective. 7th ed. Upper Saddle River, NJ:Pearson Education, 2010. 